\title{
Utility of sun-reactive skin typing and melanin index for discerning vitamin $D$ deficiency
}

\author{
Arshad T. Khalid ${ }^{1}$, Charity G. Moore ${ }^{2}$, Christopher Hall ${ }^{1}$, Flora Olabopo ${ }^{1}$, Nigel L. Rozario ${ }^{2}$, Michael F. Holick ${ }^{3}$, \\ Susan L. Greenspan ${ }^{4}$ and Kumaravel Rajakumar ${ }^{1}$
}

BACKGROUND: Skin color, a vitamin D status determinant, can be assessed subjectively by Fitzpatrick sun-reactive skin typing (FST) and objectively by melanin index (MI). FST was validated against $\mathrm{Ml}$ for discerning vitamin $\mathrm{D}$ deficiency (serum 25-hydroxyvitamin D $(25(\mathrm{OH}) \mathrm{D})<20 \mathrm{ng} / \mathrm{ml})$ in children.

METHODS: We measured FST, MI, and serum 25(OH)D in healthy, 8- to 18-year-old children from one of two vitamin D trials. MI from forehead, hand, and upper arm split at the median of the more racially balanced study cohort and FST (IIII vs. IV-V) were used for discriminating vitamin D deficiency. RESULTS: A total of 296 participants (mean age, $12.3 \pm 2.3$ years; black, 208; FST IV-V, 209; 25(OH)D <20 ng/ml, 159) were studied. MI and FST had a strong positive association. Serum 25(OH)D was negatively associated with $\mathrm{Ml}$ and FST. Sensitivity, specificity, and predictive values were similar for discriminating vitamin D deficiency between higher vs. lower MI and between FST I-III VS. IV-V. ROC area under the curves for FST (0.59) and MI (forehead (0.63); hand (0.62); and arm (0.64)) were similar.

CONCLUSIONS: FST is comparable to Ml for discerning vitamin $D$ deficiency and can be deemed as an inexpensive, useful surrogate measure of skin color in the context of vitamin $D$ research.

A sufficient vitamin D status is necessary for healthy skeletal growth and calcium equilibrium. However, variability in diet, skin color, geography, and sunlight exposure can predispose otherwise healthy children to hypovitaminosis D (1-3). Concentration of serum 25hydroxyvitamin $\mathrm{D}(25(\mathrm{OH}) \mathrm{D})$ is an established biomarker of vitamin $\mathrm{D}$ status; the Institute of Medicine defines a 25 $(\mathrm{OH}) \mathrm{D}$ concentration $\geqslant 20 \mathrm{ng} / \mathrm{ml}$ as sufficient for skeletal growth and development (4).

Skin color is an important determinant of vitamin D photosynthesis. Melanin pigment, the principal determinant of skin color, can compromise vitamin D photoproduction in the skin by serving as a natural filter of solar ultraviolet-B radiation in the epidermis (5-7). Melanin is produced by melanocytes in the epidermis and is stored in melanosomes of the stratum basale. Dark-skinned individuals have an abundance of melanin, and their melanin-laden melanosomes are distributed diffusely and uniformly. On the contrary, light-skinned individuals have relatively less melanin and a sparser distribution of melanosomes $(8,9)$. Dark-skinned individuals, as a result of increased skin melanin content, are at a higher risk for hypovitaminosis D $(10,11)$.

Skin color can be quantified by reflectance photometric techniques including tristimulus colorimetry and narrowband spectrophotometry. Narrow-band spectrophotometric devices compute melanin index (MI) as an objective measure of the skin melanin content. Although MI can serve as an objective measure of an individual's skin color in the context of vitamin D research (12-15), the cost and effort of such measurement may pose a barrier for their widespread use. Therefore, inexpensive alternate skin color assessment techniques are needed to gain similar information with comparable effectiveness.

Fitzpatrick sun-reactive skin typing (FST) is a categorical scale of patient-reported perceptions of skin sensitivity and reactivity to sunlight exposure and has been widely used in vitamin $\mathrm{D}$ clinical research as an inexpensive surrogate for skin color assessment (16-18). Although it was originally devised in the treatment of psoriasis, it has been utilized in various medical contexts ranging from its role in laser hair removal to risk factors in skin cancers $(16,19-22)$. Skin types are categorized as I through $\mathrm{V}$ based on a combination of sun sensitivity (sunburn response) and reactivity (pigmentary or tanning response). Individuals with skin type I readily burn when exposed to sunlight and resist tanning on repeated exposures; those individuals with skin type $\mathrm{V}$ do not sunburn during sun exposure and undergo a considerable pigmentary response (sun tan) to subsequent exposures. To our knowledge, this subjective surrogate measure remains to be validated against objective measures of skin color in the context of vitamin $\mathrm{D}$ research in children. Therefore, we have sought to validate the utility of parent-reported, Fitzpatrick

\footnotetext{
${ }^{1}$ Department of Pediatrics, University of Pittsburgh, Pittsburgh, Pennsylvania; ${ }^{2}$ Center for Outcomes Research and Evaluation, Carolinas HealthCare System, Charlotte, North Carolina; ${ }^{3}$ Department of Medicine, Boston University School of Medicine, Boston, Massachusetts; ${ }^{4}$ Department of Medicine, University of Pittsburgh, Pittsburgh, Pennsylvania. Correspondence: Kumaravel Rajakumar (Kumaravel.Rajakumar@chp.edu) 
sun-reactive skin type against $\mathrm{MI}$ in discerning vitamin $\mathrm{D}$ deficiency.

\section{METHODS}

\section{Study Design and Participants}

We conducted a cross-sectional study of healthy 8- to 18-year-old children at the Children's Hospital of Pittsburgh of University of Pittsburgh Medical Center. The study cohort comprised a convenience sample of children with baseline assessments collected during participation in one of two NIH-funded vitamin D clinical trials. Study 1 examined the efficacy of vitamin D supplementation in healthy 8- to 14-year-old black and white children enrolled during October 2008 through March 2011 (ref. 23). Study 2 (Clinicaltrials. gov identifier: NCT01797302) is ongoing since August 2013 and examines the cardiometabolic benefits of enhanced vitamin D supplementation in otherwise healthy vitamin D-deficient obese or overweight 10 - to 18 -year-old children. Studies were approved by the University of Pittsburgh Institutional Review Board. Parental consent and participant's assent were obtained prior to participation. Children's race was specified by their parents.

\section{Study Measurements}

Our study measurements included anthropometric measurements, FST, MI, and serum 25-hydroxyvitamin D concentration. Children's height and weight were measured, and BMI was calculated.

Fitzpatrick sun-reactive skin type. Skin type was estimated by the subjects or their parents in response to a questionnaire (16). Classification on a scale of I-V was based on (i) subjects' degree of sunburn after the first $30-45 \mathrm{~min}$ of sun exposure-without sunscreen use-at the beginning of summer and (ii) their respective tanning response after repeated exposures. Skin types IIII are typically associated with lighter skin tones, and skin types IV$\mathrm{V}$ are associated with darker skin tones (16-18) - type I (easy burn, no $\tan$ ), type II (easy burn, slight tan), type III (burn, then tan), type IV (no burn, good tan), and type V (never burn, marked tan).

Melanin index. We used a hand-held dermaspectrometer (DSM II Colormeter, Cortex Technology, Hadsund, Denmark) to estimate the subjects' MI (12-15). The device was calibrated prior to use against a manufacturer-provided white calibration plate. The colorimeter's narrow-band reflectance system utilizes two high-intensity white light-emitting diodes to reflect light onto a $7-\mathrm{mm}^{2}$ target area of the subjects' skin. An RGB (Red-Green-Blue) sensor determines the intensities of the red $\left(I_{\text {red }}\right)$, green, and blue lights being reflected back, which were used to compute specific skin indices including the MI.

$$
\mathrm{MI}=100 \times \log \frac{1}{I_{\text {red }}}
$$

Measurements were taken three times from the forehead, the back of the hand, and inside of the upper arm and averaged. Measurements from forehead and back of the hand were reflective of skin color modified by ultraviolet radiation (facultative pigmentation), and measurements from arm were indicative of innate skin color (constitutive pigmentation).

Serum 25(OH)D. Serum 25(OH)D was measured using liquid chromatography tandem mass spectrometry assay. Assays for Study 1 participants were performed at Vitamin D, Skin, and Bone Research Laboratory at the Boston University Medical Center and those for Study 2 participants were performed at the University of Pittsburgh Medical Center Clinical Chemistry Laboratory as previously described $(23,24)$. Vitamin $\mathrm{D}$ deficiency was defined as serum $25(\mathrm{OH}) \mathrm{D}$ concentration $<20 \mathrm{ng} / \mathrm{ml}$ (ref. 4).

\section{Statistical Analysis}

We first compared the children from the two studies on demographics and clinical characteristics using two-sample $t$-tests for continuous measures (or Wilcoxon Rank Sum tests for skewed data) and $\chi^{2}$-tests for categorical measures. We estimated the correlation among melanin measures, skin type, and serum $25(\mathrm{OH})$ $\mathrm{D}$ concentrations using Pearson or Spearman correlations. The median MI value from the Study 1 cohort was chosen as the cutpoint for dichotomization of the MI of all participants as this subset was more racially balanced with nearly equal numbers of black and white children. The skin types were dichotomized as I-III (light-skinned) vs. IV-V (dark-skinned). We then calculated sensitivity, specificity, positive predictive value (PPV), and negative predictive value (NPV) for each skin measure for predicting vitamin $\mathrm{D}$ deficiency. Corresponding $95 \%$ confidence intervals were calculated as well. Seasonality was tested by combining seasons into a Summer/Fall group and a winter/spring group. ANOVA was used to compare the serum $25(\mathrm{OH}) \mathrm{D}$ concentrations between seasons within skin color groups and between skin color groups within seasons. Finally, we estimated the predictive value of each skin measure using logistic regression and area under the receiver operating characteristic (ROC) curve and the corresponding 95\% interval. All analyses were conducted using the SAS Enterprise Guide version 6.1, and all tests were two-sided $(\alpha=0.05)$.

\section{RESULTS}

We studied a cross-sectional sample of 296 children enrolled in one of the two vitamin D clinical trials (Study 1, $n=150$; Study 2, $n=146)$. Demographic characteristics, mean $25(\mathrm{OH})$ $\mathrm{D}$ concentrations, and vitamin $\mathrm{D}$ status of all participants, and each of the subsamples that comprised this cohort are shown in Table 1. The pooled cohort had a mean age of $12.3 \pm 2.3$ years and majority of the children were female (55\%), black (70\%), with skin types IV-V (71\%), and vitamin D-deficient (54\%). The mean $25(\mathrm{OH}) \mathrm{D}$ concentration of all participants was $19.7 \pm 7.3 \mathrm{ng} / \mathrm{ml}$. Participants from Study 2, when compared with those from Study 1, were significantly older and had a higher representation of children who were black and who had darker skin tones (i.e., higher MI and skin types IV-V). MI measurements were available in 278 children, and skin type classification was available in all children. Of the 278 children with MI measurements, 153 (55\%) were vitamin D-deficient and, of the 296 children with skin type classifications, 159 (54\%) were vitamin D-deficient.

\section{Significant Correlations}

MI measurements had a strong positive association with skin type at all three sites (forehead, $r=0.66, P<0.0001$; hand, $r=0.67, P<0.0001$; and upper arm, $r=0.65, P<0.0001$ ). Serum $25(\mathrm{OH}) \mathrm{D}$ concentrations were negatively associated with MI measurements at the forehead $(r=-0.30$, $P<0.0001)$, hand $(r=-0.29, P<0.0001)$, and upper arm $(r=-0.31, P<0.0001)$. Serum 25(OH)D concentrations were also negatively associated with skin type $(r=-0.20$, $P=0.0006$; shown in Figure 1).

\section{Vitamin D Status by Skin Color and Skin Type}

Vitamin D status (serum 25(OH)D $<20 \mathrm{vs}$. $\geqslant 20 \mathrm{ng} / \mathrm{ml}$ ) of children stratified by skin type (I-III vs. IV-V) and skin color (MI below vs. at or above the median of Study 1 participants) is shown in Table 2. Rates of vitamin D deficiency were higher in children with skin types IV-V and MI at or above 


\section{Articles | Khalid et al.}

Table 1. Subjects' characteristics

\begin{tabular}{|c|c|c|c|c|}
\hline & $\begin{array}{c}\text { All subjects; } N=296 ; N(\%), \\
\text { mean } \pm S D, \text { or median } \\
\left(25^{\text {th }} \text { to } 75^{\text {th }} \text { quartile }\right)\end{array}$ & $\begin{array}{l}\text { Study } 1 \text { subjects; } N=154 ; N(\%) \text {, } \\
\text { mean } \pm S D \text {, or median } \\
\left(25^{\text {th }} \text { to } 75^{\text {th }} \text { quartile }\right)\end{array}$ & $\begin{array}{l}\text { Study } 2 \text { subjects; } N=142 ; n(\%), \\
\text { mean } \pm S D \text {, or median } \\
\left(25^{\text {th }} \text { to } 75^{\text {th }} \text { quartile }\right)\end{array}$ & $\begin{array}{l}\text { Study } 1 \text { vs. } 2 ; \\
P \text { value }\end{array}$ \\
\hline Age (years) & $12.3 \pm 2.3$ & $11.3 \pm 1.9$ & $13.4 \pm 2.1$ & $<0.0001$ \\
\hline Male & $134(45)$ & $76(49)$ & $58(41)$ & 0.14 \\
\hline Race & & & & $<0.0001$ \\
\hline Black & $208(70)$ & $83(54)$ & $125(88)$ & \\
\hline White & $82(28)$ & $71(46)$ & $11(8)$ & \\
\hline Other & $6(2)$ & 0 & $6(4)$ & \\
\hline \multicolumn{5}{|l|}{ Ethnicity } \\
\hline Hispanic & $14(5)$ & $2(1)$ & $12(8)$ & \\
\hline Weight (kg) & $63.8 \pm 25.1$ & $48.8 \pm 18.5$ & $80.1 \pm 20.8$ & $<0.0001$ \\
\hline Height (cm) & $154.6 \pm 13.3$ & $148.8 \pm 13.1$ & $160.9 \pm 10.4$ & $<0.0001$ \\
\hline BMI & $25.9 \pm 7.4$ & $21.5 \pm 5.8$ & $30.6 \pm 5.8$ & $<0.0001$ \\
\hline Skin type & & & & $<0.0001$ \\
\hline I (easy burn, no tan) & $11(4)$ & $10(6)$ & $1(1)$ & \\
\hline II (easy burn, slight tan) & $32(11)$ & $27(18)$ & $5(4)$ & \\
\hline III (burn, then tan) & $44(15)$ & $31(20)$ & $13(9)$ & \\
\hline IV (no burn, good tan) & $136(46)$ & $63(41)$ & $73(51)$ & \\
\hline V (never burn, marked tan) & $73(24)$ & $23(15)$ & $50(35)$ & \\
\hline \multicolumn{5}{|l|}{ Melanin index } \\
\hline Forehead & $59.3(39.3-73)$ & $49.1(35.1-68.8)$ & $65(53.4-75.5)$ & $<0.0001$ \\
\hline Hand & $63.2(43.2-75.2)$ & $52.3(38-72.5)$ & $67.7(57.3-76.8)$ & $<0.0001$ \\
\hline Upper arm & $58(38.8-69)$ & $47.6(36-67.6)$ & $62.3(53-72)$ & $<0.0001$ \\
\hline $\begin{array}{l}\text { Mean serum } 25(\mathrm{OH}) \mathrm{D} \\
(\mathrm{ng} / \mathrm{ml})\end{array}$ & $19.7 \pm 7.3$ & $19.4 \pm 7.2$ & $20 \pm 7.4$ & 0.46 \\
\hline Serum 25(OH)D (ng/ml) & & & & 0.77 \\
\hline$<20$ (deficient) & $159(54)$ & $84(55)$ & $75(53)$ & \\
\hline$\geqslant 20$ (non-deficient) & $137(46)$ & $70(45)$ & $67(47)$ & \\
\hline
\end{tabular}

25(OH)D, 25-hydroxyvitamin D.

the median. The proportion of vitamin D-deficient and vitamin $\mathrm{D}$-non-deficient children across the skin type strata and MI strata was similar.

Prediction of Vitamin D Deficiency by Skin Type and Skin Color The diagnostic characteristics (sensitivity, specificity, PPV, and NPV) of skin type and skin color for the prediction of vitamin $\mathrm{D}$ deficiency are shown in Table 3. Both MI (forehead, hand, and upper arm) and FST had similar diagnostic characteristics for discerning vitamin $\mathrm{D}$ deficiency. ROC curves comparing the degree of diagnostic accuracy for these measures are shown in Figure 2, and respective areas under the curves for these measures are shown in Table 3 .

\section{Season, Skin Color, and Vitamin D Status}

The mean serum $25(\mathrm{OH}) \mathrm{D}$ concentrations in children examined during winter/spring (January-June) were lower or trended to be lower when compared with those in children who were assessed during summer/fall (July-December) within each of the respective skin type (I-III and IV-V) and skin color strata $(\mathrm{MI}<$ median, and $\mathrm{MI} \geqslant$ median; data 

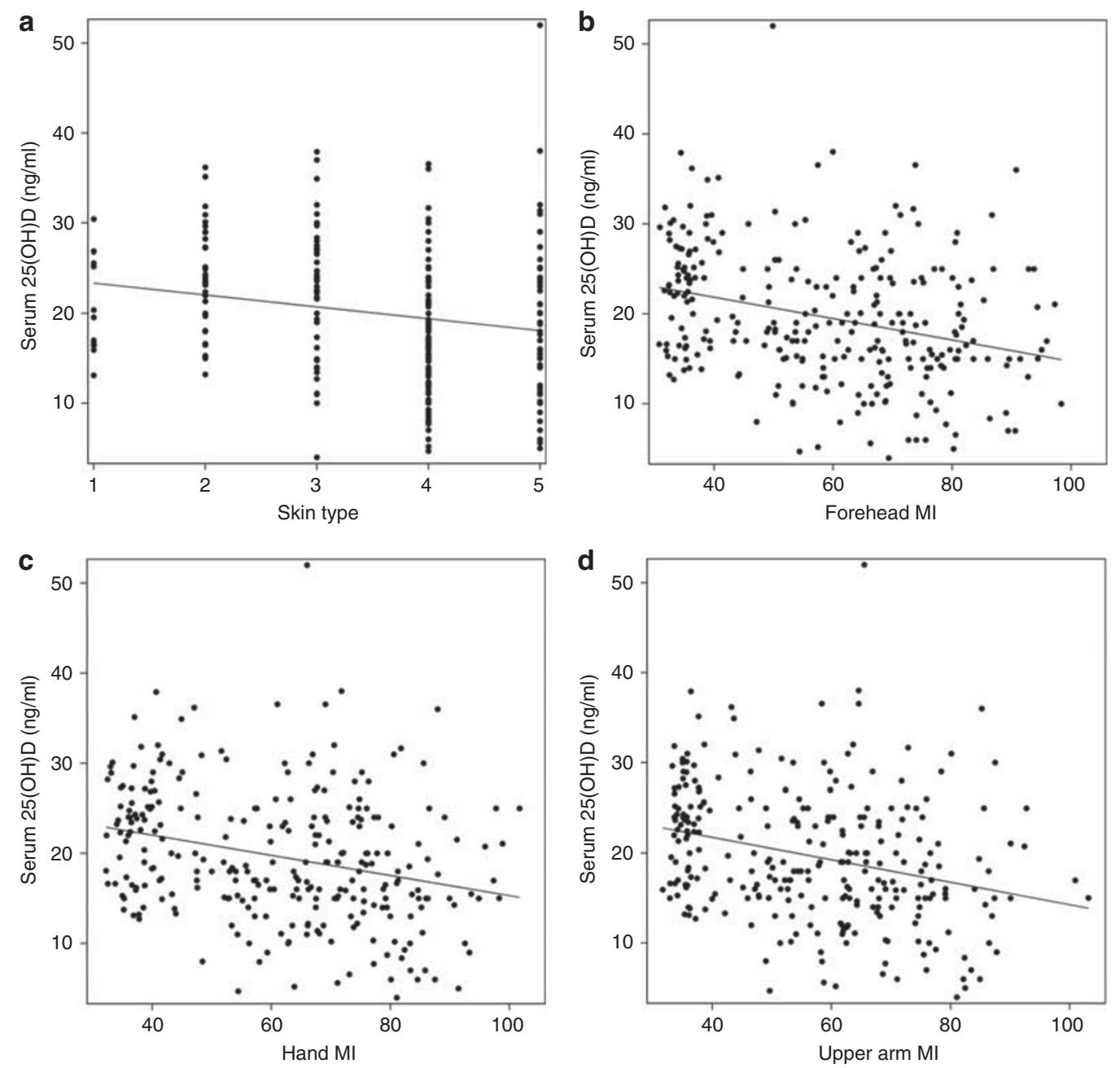

Figure 1. Serum $25(\mathrm{OH}) \mathrm{D}$ and skin color correlations: (a) skin type, (b) forehead melanin index, (c) hand melanin index, and (d) upper arm melanin index. 25(OH)D, 25-hydroxyvitamin D.

Table 2. $25(\mathrm{OH}) \mathrm{D}$ status stratified by high vs. low skin type and high vs. low MI

\begin{tabular}{|c|c|c|c|}
\hline & $\begin{array}{l}\text { Stratification; } \\
\text { strata }(N)\end{array}$ & $\begin{array}{c}<20 \mathrm{ng} / \mathrm{ml}, \\
\text { deficient; } n(\%)\end{array}$ & $\begin{array}{c}\geqslant 20 \mathrm{ng} / \mathrm{ml}, \\
\text { non-deficient } \\
n(\%)\end{array}$ \\
\hline \multirow[t]{2}{*}{ Skin type } & I-III (87) & $32(37 \%)$ & $55(63 \%)$ \\
\hline & IV-V (209) & $127(61 \%)$ & $82(39 \%)$ \\
\hline \multirow[t]{2}{*}{ Forehead MI } & $\mathrm{MI}<$ median $^{\mathrm{a}}(94)$ & $34(36 \%)$ & $60(64 \%)$ \\
\hline & $\begin{array}{c}\mathrm{MI} \geqslant \operatorname{median}^{\mathrm{a}} \\
(184)\end{array}$ & $119(65 \%)$ & $65(35 \%)$ \\
\hline \multirow[t]{2}{*}{ Hand MI } & $\mathrm{Ml}<$ median $^{\mathrm{b}}(90)$ & $33(37 \%)$ & $57(63 \%)$ \\
\hline & $\mathrm{Ml} \underset{(188)}{\operatorname{median}^{\mathrm{b}}}$ & $120(64 \%)$ & $68(36 \%)$ \\
\hline \multirow[t]{2}{*}{ Upper arm Ml } & $\mathrm{Ml}<$ median $^{c}$ (94) & $35(37 \%)$ & $59(63 \%)$ \\
\hline & $\begin{array}{c}M I \geqslant \operatorname{median}^{c} \\
(183)\end{array}$ & 117 (64\%) & $66(36 \%)$ \\
\hline
\end{tabular}

$\mathrm{Ml}$, melanin index; 25(OH)D, 25-hydroxyvitamin $\mathrm{D}$.

Melanin indices were dichotomized at the median of the more racially balanced Study 1 cohort.

Site (median MI (25th to 75 th quartile)).

aForehead (49 (35-69)).

bHand $(52(38,72))$.

CUpper arm $(48(36,68))$. shown in Supplementary Table S1 online). Dark-skinned children (i.e., skin types IV-V; $\mathrm{MI} \geqslant$ median) when compared with light-skinned children (i.e., skin types I-III; $\mathrm{MI}<$ median) had lower mean serum 25(OH)D concentrations during both winter/spring and summer/fall. Box plots of the serum $25(\mathrm{OH}) \mathrm{D}$ concentrations by season and skin type or color are shown in Figure 3.

\section{DISCUSSION}

We found Fitzpatrick sun-reactive skin type and MI to have similar diagnostic characteristics for distinguishing vitamin D deficiency in children. Both measures had a relatively higher sensitivity (skin type, 80\%; MI, 77-78\%) and lower specificity (skin type, 40\%; MI, 46-48\%). The PPV and NPV of these two measures were modest (PPV-skin type, 61\%; MI, 64-65\% and NPV-skin type, 63\%; MI, 63-64\%, respectively). In addition, we found a strong positive association between skin type and MI at sites representing facultative or constitutive pigmentation. These findings would indicate that both Fitzpatrick sun-reactive skin type and MI can be equally effective for 


\section{Articles | Khalid et al.}

Table 3. Prediction of $25(\mathrm{OH}) \mathrm{D}<20 \mathrm{ng} / \mathrm{ml}$ between high vs. low $\mathrm{Ml}$ and high vs. low skin type

\begin{tabular}{|c|c|c|c|c|c|}
\hline & Se; \% (95\% Cl) & $\mathrm{Sp} ; \%(95 \% \mathrm{Cl})$ & PPV; \% (95\% Cl) & NPV; \% (95\% Cl) & $\mathrm{ROC}$ model; AUC $\pm \mathrm{SE}(95 \% \mathrm{Cl})$ \\
\hline Skin types I-III vs. IV-V & $80(74,86)$ & $40(32,48)$ & $61(54,67)$ & $63(53,73)$ & $0.59 \pm 0.033(0.53,0.66)$ \\
\hline Forehead MI & $78(71,84)$ & $48(39,57)$ & $65(58,72)$ & $64(54,74)$ & $0.63 \pm 0.034(0.56,0.70)$ \\
\hline Hand MI & $78(72,85)$ & $46(37,54)$ & $64(57,71)$ & $63(53,73)$ & $0.62 \pm 0.034(0.55,0.69)$ \\
\hline Upper arm MI & $77(70,84)$ & $47(38,56)$ & $64(57,71)$ & $63(53,73)$ & $0.64 \pm 0.034(0.57,0.70)$ \\
\hline
\end{tabular}

AUC, area under the curve; $\mathrm{Cl}$, confidence interval; Ml, melanin index; NPV, negative predictive value; 25(OH)D, 25-hydroxyvitamin D; PPV, positive predictive value; Se, sensitivity; Sp, specificity.
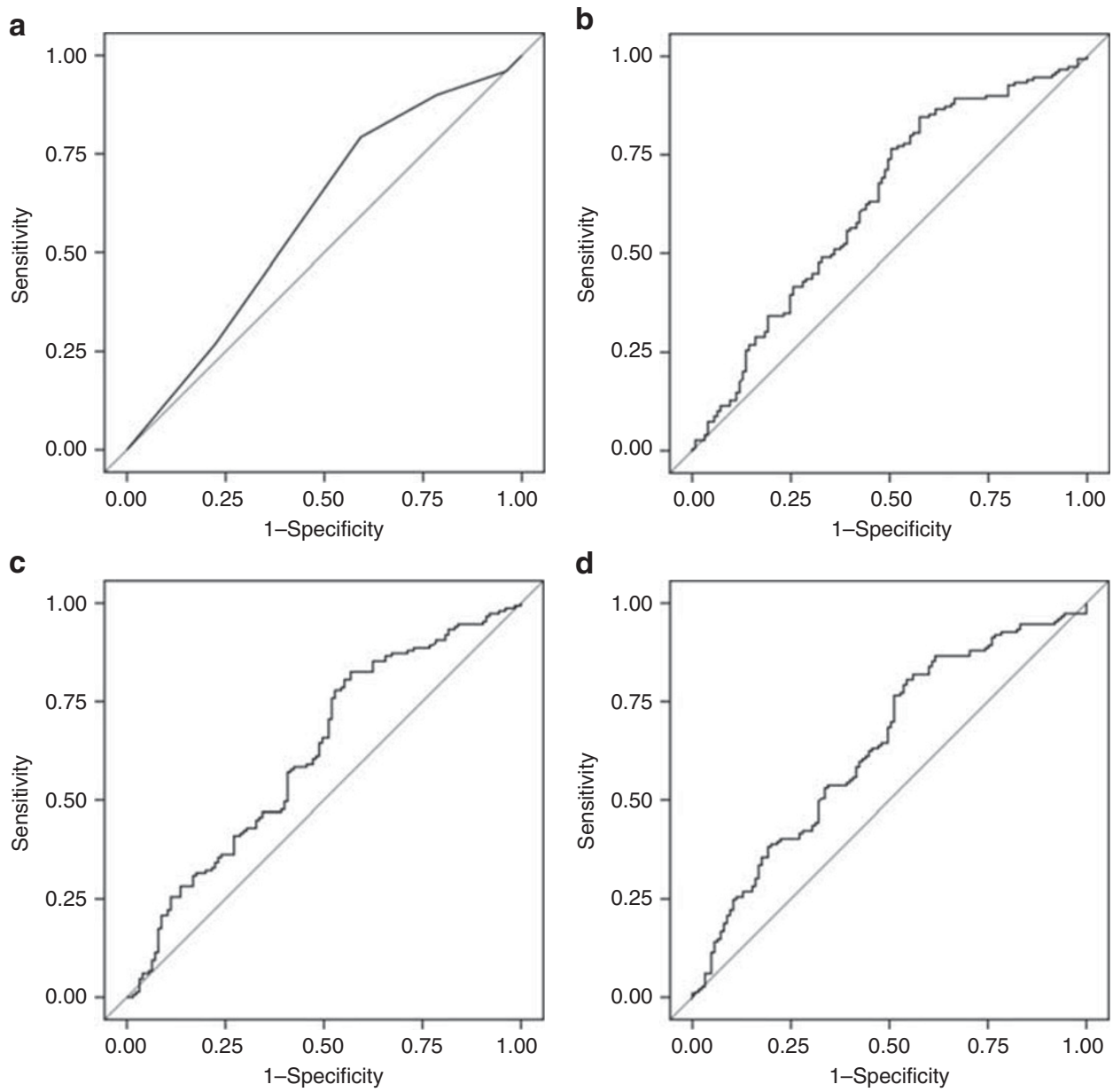

Figure 2. ROC curves (AUC ( $95 \% \mathrm{CI})$ ) for discerning vitamin D deficiency by skin color: (a) skin types I-III vs. IV-V (0.59 (0.53, 0.66)), (b) forehead melanin index $(0.63(0.56,0.70))$, (c) hand melanin index $(0.62(0.55,0.69))$, and (d) upper arm melanin index (0.64 (0.57, 0.70$))$. AUC, area under the curve; $\mathrm{Cl}$, confidence interval; $\mathrm{ROC}$, receiver operating characteristic.

assessment of skin color phenotypes in the context of vitamin D research.

Our findings also indicate both $\mathrm{MI}$ and skin type to be negatively associated with serum $25(\mathrm{OH}) \mathrm{D}$ concentrations. In addition, both MI and skin type had a high degree of sensitivity and modest positive and negative predictive values for distinguishing vitamin D-deficient status. Together, these findings highlight the relevance of skin pigmentation as an important determinant of vitamin $\mathrm{D}$ status in children. The availability of ultraviolet-B radiation is an overarching determinant for adequate vitamin $\mathrm{D}$ production and is driven by many variables including latitude of residence, season, atmospheric conditions, lifestyle (sun screen use, clothing, and sunlight exposure), and skin color $(1-3,11,25,26)$. In addition, dietary intake of vitamin $\mathrm{D}$, adiposity, age, and pubertal status are also relevant determinants of vitamin D status (24,27-29). Therefore, it is not surprising that our prediction model that examined only "skin color" was modest at best for discerning vitamin $\mathrm{D}$ deficiency.

To our knowledge, this study is the first to validate Fitzpatrick sun-reactive skin type against $\mathrm{MI}$ in the context of vitamin $\mathrm{D}$ research in children and to examine their 

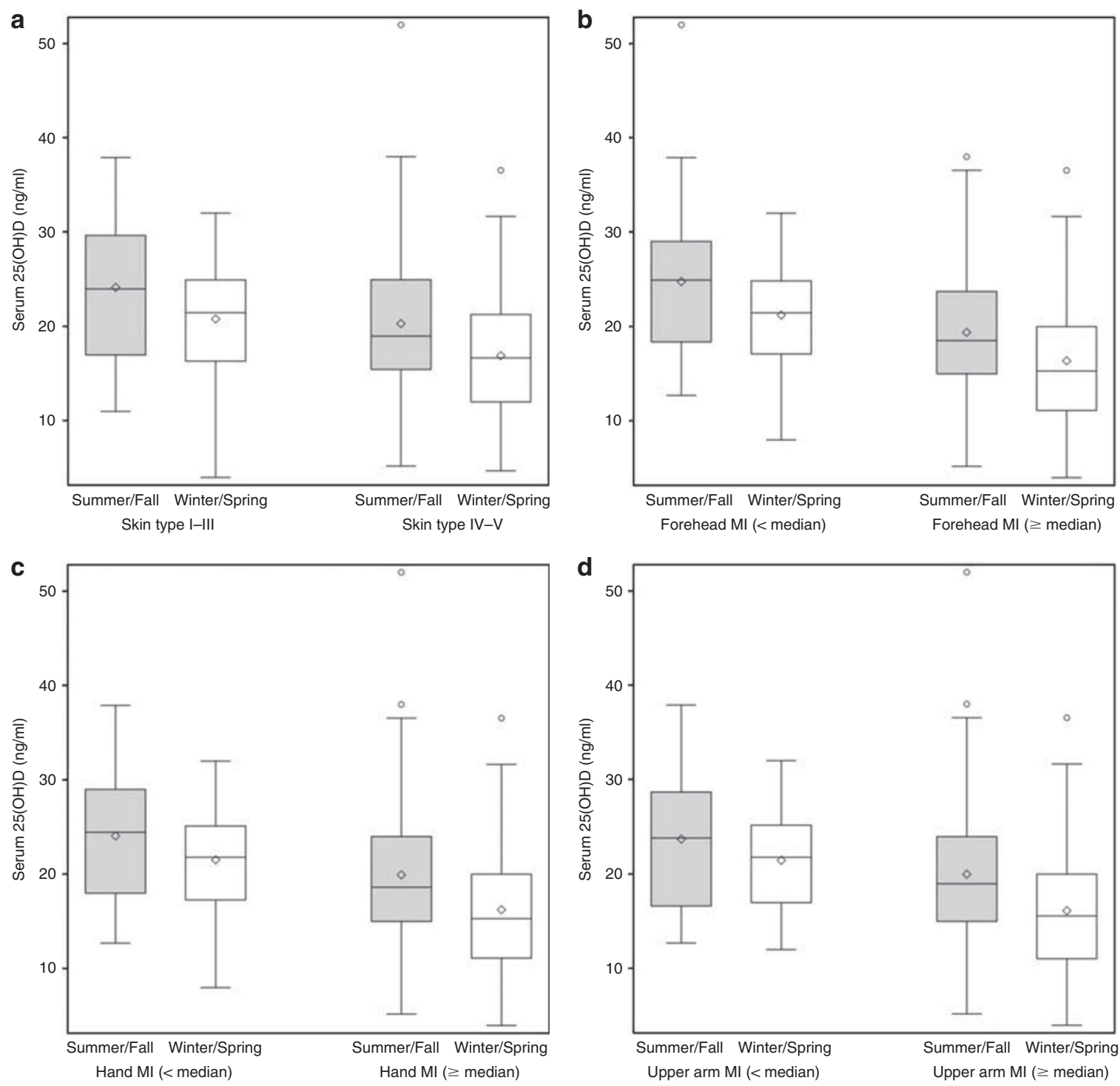

Figure 3. Box plots of the serum 25(OH)D concentrations by skin color and season: (a) skin types I-III vs. IV-V, (b) forehead melanin index ( $<$ median vs. $\geqslant$ median), (c) hand melanin index (<median vs. $\geqslant$ median), and (d) upper arm melanin index (<median vs. $\geqslant$ median). The box represents the 25th to 75 th quartile range split at the median (50th percentile); means are denoted by diamonds. Shaded boxes indicate $25(\mathrm{OH}) \mathrm{D}$ concentrations during summer/fall, whereas unshaded boxes indicate 25(OH)D concentrations during winter/spring. The whiskers represent the maximum and minimum range of the data sets exclusive of outliers. Statistical outliers are shown as circles. 25(OH)D, 25-hydroxyvitamin D.

diagnostic accuracy for discerning vitamin D deficiency. The enrollment of a racially diverse cohort of large number of children across the skin phenotype spectrum with significant proportion of vitamin D deficiency contributed to the strength of this study. Limitations of our study are inherent to our study design - we acknowledge that our findings could vary based on the cutpoints of MI and 25(OH)D chosen for the prediction of vitamin $\mathrm{D}$ deficiency. However, we have offset these limitations by using a conservative definition of vitamin D deficiency (serum $25(\mathrm{OH}) \mathrm{D}<20 \mathrm{ng} / \mathrm{ml}$ ) based on Institute of Medicine-set threshold concentrations. The MI cutpoint was chosen from the more racially balanced Study 1 participant subset. Furthermore, it is reassuring that the chosen MI cutpoints were similar to the skin type stratification (I-III vs. IV-V) in categorizing the proportion of vitamin $\mathrm{D}$ deficiency (Table 2). Our observation of the widespread distribution of serum $25(\mathrm{OH}) \mathrm{D}$ concentrations within each of the skin types and values of MI (Figure 1) indicates that Fitzpatrick skin type and MI may not have the same predictive value for identifying vitamin $\mathrm{D}$ deficiency if the study population is homogenous in skin type or MI. Fitzpatrick skin type and MI may be better predictors of vitamin D deficiency in cohorts with diverse skin colors or sun-reactive skin types, as reflected in our study.

Our study design rendered the opportunity to examine the effect of season on vitamin D status by skin color. Mean 


\section{Articles | Khalid et al.}

serum 25(OH)D concentration was generally lower during winter/spring compared with that during summer/fall in both light- and dark-skinned children. Dark-skinned children had lower mean serum 25(OH)D concentration than lightskinned children during both winter/spring and summer/fall. The 25(OH)D concentrations in dark-skinned children during summer/fall were consistently lower than the 25 $(\mathrm{OH}) \mathrm{D}$ concentrations in light-skinned children during winter/spring. This suggests that the seasonal surge in the $25(\mathrm{OH}) \mathrm{D}$ concentrations during summer/fall in dark-skinned children was not adequate to offset their disadvantage in vitamin $\mathrm{D}$ photoproduction. These findings emphasize the relevance of season and skin color in the determination of vitamin $\mathrm{D}$ status in children and affirm our previously published findings $(11,27)$.

The excessive prevalence of vitamin $\mathrm{D}$ deficiency in our study population (serum 25(OH)D concentrations $<20 \mathrm{ng} /$ $\mathrm{ml}, 54 \%)$ can be ascribed to our study design and subject selection, and include the following: (i) enrollment of children in Study 1 only during October through March, a vulnerable period for seasonal hypovitaminosis D in Pittsburgh, PA (latitude: $40.4^{\circ} \mathrm{N}$; (refs 11,23)); (ii) inclusion of only children who were obese or overweight (mean BMI 30.6) in Study 2, a group vulnerable for hypovitaminosis D secondary to excess adiposity (27); and (iii) overall higher representation of black children (70\%) and children with skin types IV and V (70\%) in the combined cohort, a group vulnerable for compromised vitamin $\mathrm{D}$ photosynthesis secondary to excess skin melanin content $(27,30)$.

When examining the utility of FST, it is necessary to acknowledge the inherent limitations of this measure. Skin phototyping is susceptible to difficulties in reproducibility due to the structure of the questions and the available responses (31). Given the limited categorical responses available, participants may have difficulty selecting from a single skin type to describe their burning and tanning responses. Rampen et al. (32) collected burning and tanning histories from 18- to 30 -year-old white adults and found that of 790 subjects only $41 \%$ could be classified according to the Fitzpatrick sunreactive skin type scale; tanning response was better associated with skin color than burning response. How the questions regarding sun sensitivity and tanning responses are interpreted can result in misclassification bias. Recall bias may also detract from reproducibility. Subjects can have difficulty remembering how long it takes for their skin to burn after an initial exposure or the timeline for their tanning response $(31,33)$. Fitzpatrick skin typing is vulnerable to misclassification in Hispanics and Asians as their skin phototype is poorly correlated with their facultative and constitutive skin color (34-36). Despite these limitations, our findings of a strong positive association between skin phototyping and objective MI measures in a racially diverse cohort reassert the value of Fitzpatrick skin typing in the context of vitamin D research. However, further research is necessary to account for the inherent limitations of this instrument.
We conclude that Fitzpatrick sun-reactive skin type, an inexpensive surrogate measure of skin color, is comparable to MI in discerning vitamin D deficiency in the context of vitamin $\mathrm{D}$ research in cohorts of children with diverse skin colors or sun-reactive skin types. However, MI can provide nuanced information regarding the role of constitutive and facultative skin color for assessing vitamin D status and in determining vitamin $\mathrm{D}$ requirements $(15,37)$. Future studies are warranted to examine whether inclusion of other determinants of vitamin $\mathrm{D}$ status in addition to skin color can improve the prediction of vitamin D deficiency.

\section{SUPPLEMENTARY MATERIAL}

Supplementary material is linked to the online version of the paper at http://www.nature.com/pr

\section{ACKNOWLEDGMENTS}

We thank Gary Grove of CyberDerm for his valuable editorial suggestions and for sharing his expertise in skin color assessment methods.

\section{STATEMENT OF FINANCIAL SUPPORT}

This work was supported by the following grants: National Institutes of Health grants K23HD052550 (K.R.), K24DK062895 (S.L.G.), P30 AG024827 (S.L.G.), R01HL112985 (K.R., C.G.M.), and UL1 RR024153 (University of Pittsburgh Clinical and Translational Research Center and Pediatric PittNet); and Children's Hospital of Pittsburgh Research Advisory Committee seed grant (K.R.).

Disclosure: The authors declare no conflict of interest.

\section{REFERENCES}

1. Stamp TC, Round JM. Seasonal changes in human plasma levels of 25hydroxyvitamin D. Nature 1974;247:563-5.

2. Holick MF, MacLaughlin JA, Clark MB, et al. Photosynthesis of previtamin D3 in human skin and the physiologic consequences. Science 1980;210:203-5.

3. Webb AR, Kline L, Holick MF. Influence of season and latitude on the cutaneous synthesis of vitamin D3: exposure to winter sunlight in Boston and Edmonton will not promote vitamin D3 synthesis in human skin. J Clin Endocr Metab 1988;67:373-8.

4. Institute of Medicine. Dietary Reference Intakes for Calcium and Vitamin D. Washington, DC: The National Academies Press, 2011.

5. Norman AW. Sunlight, season, skin pigmentation, vitamin D, and 25hydroxyvitamin D: integral components of the vitamin D endocrine system. Am J Clin Nutr 1998;67:1108-10.

6. Misra M, Pacaud D, Petryk A, Collett-Solberg PF, Kappy M. Vitamin D deficiency in children and its management: review of current knowledge and recommendations. Pediatrics 2008;122:398-417.

7. Holick MF, MacLaughlin JA, Doppelt S. Regulation of cutaneous previtamin D3 photosynthesis in man: skin pigment is not an essential regulator. Science 1981;211:590-3.

8. Kaidbey KH, Agin PP, Sayre RM, Kligman AM. Photoprotection by melanin-a comparison of black and Caucasian skin. J Am Acad Dermatol 1979;1:249-60.

9. Robins AH. Biological Perspectives on Human Pigmentation. New York, NY; Cambridge University Press, 2005:1-18.

10. Rajakumar K, Fernstrom JD, Janosky JE, Greenspan SL. Vitamin D insufficiency in preadolescent African-American children. Clin Pediatr 2005;44:683-92.

11. Rajakumar K, Holick MF, Jeong K, et al. Impact of season and diet on vitamin D status of African American and Caucasian children. Clin Pediatr 2011;50:493-502. 


\section{\begin{tabular}{l|l} 
Skin color and vitamin D deficiency & Articles
\end{tabular}}

12. Clarys P, Alewaeters K, Lambrecht R, Barel A. Skin color measurements: comparison between three instruments: the Chromameter, the DermaSpectrometer and the Mexameter. Skin Res Technol 2000;6:230-8.

13. Farr PM, Diffey BL. Quantitative studies on cutaneous erythema induced by ultraviolet radiation. Br J Dermatol 1984;111:673-82.

14. Diffey BL, Oliver RJ, Farr PM. A portable instrument for quantifying erythema induced by ultraviolet radiation. Br J Dermatol 1984;111: 663-72.

15. Fullerton A, Fischer T, Lahti A, Wilhelm KP, Takiwaki H, Serup J. Guidelines for measurement skin colour and erythema; a report from the Standardization Group of the European Society of Contact Dermatitis. Contact Dermatitis 1996;35:1-10.

16. Fitzpatrick TB. The validity and practicality of sun-reactive skin types I through VI. Arch Dermatol 1988;124:869-71.

17. Pathak MA, Jimbow K, Szabo G, Fitzpatrick TB. Sunlight and melanin pigmentation. In: Smith KC, ed. Photochemical and Photobiological Reviews. Plenum Press: New York, NY, 1976:211-39.

18. Jimbow K, Fitzpatrick T, Wick M. Biochemistry and physiology of melanin pigmentation. In: Goldsmith LA, ed. Physiology, Biochemistry, and Molecular Biology of the Skin. New York, NY: Oxford University Press, 1991:893-909.

19. Takiwaki H, Serup J. Measurement of color parameters of psoriatic plaques by narrow-band reflectance spectrophotometry and tristimulus colorimetry. Skin Pharmacol Physiol 1994;7:145-50.

20. Rhodes AR, Weinstock MA, Fitzpatrick TB, Mihm MC, Sober AJ. Risk factors for cutaneous melanoma: a practical method of recognizing predisposed individuals. J Am Med Assoc 1987;258:3146-54.

21. Weiss RA, Weiss MA, Marwaha S, Harrington AC. Hair removal with a non-coherent filtered flashlamp intense pulsed light source. Laser Surg Med 1999;24:128-32.

22. Sitek A, Rosset I, Żądzińska E, Kasielska-Trojan A, NeskoromnaJędrzejczak A, Antoszewski B. Skin color parameters and Fitzpatrick phototypes in estimating the risk of skin cancer: a case-control study in the Polish population. J Am Acad Dermatol 2016;74:716-23.

23. Rajakumar K, Moore CG, Yabes J, et al. Effect of vitamin D3 supplementation in black and in white children: a randomized, placebo -controlled trial. J Clin Endocrinol Metabol 2015;100:3183-92.
24. Michel H, Olabopo F, Wang L, Nucci AL, Greenspan S, Rajakumar K. Determinants of 25-hydroxyvitamin D concentrations in infants and toddlers. Curr Nutr Food Sci 2015;11:124-30.

25. Matsuoka LY, Wortsman J, Dannenberg MJ, Hollis BW, Lu Z, Holick MF. Clothing prevents ultraviolet-B radiation-dependent photosynthesis of vitamin D3. J Clin Endocr Metab 1992;75:1099-3.

26. Autier P, Dore J-F, Negrier S, et al. Sunscreen use and duration of sun exposure: a double-blind, randomized trial. J Natl Cancer Inst 1999;91:1304-9.

27. Rajakumar K, de Las Heras J, Chen TC, Lee S, Holick MF, Arslanian SA. Vitamin D status, adiposity, and lipids in black American and Caucasian children. J Clin Endocr Metab 2011;96:1560-7.

28. Alemzadeh R, Kichler J, Babar G, Calhoun M. Hypovitaminosis D in obese children and adolescents: relationship with adiposity, insulin sensitivity, ethnicity, and season. Metabolism 2008;57:183-91.

29. Lenders CM, Feldman HA, Von Scheven E, et al. Relation of body fat indexes to vitamin D status and deficiency among obese adolescents. Am J Clin Nutr 2009;90:459-67.

30. Schleicher RL, Sternberg MR, Looker AC, et al. National estimates of serum total 25-hydroxyvitamin D and metabolite concentrations measured by liquid chromatography-tandem mass spectrometry in the US population during 2007-2010. J Nutr 2016;146:1051-61.

31. Ravnbak MH. Objective determination of Fitzpatrick skin type. Dan Med Bull 2010;57:B4153.

32. Rampen FH, Fleuren B, de Boo TM, Lemmens WA. Unreliability of self-reported burning tendency and tanning ability. Arch Dermatol 1988;124:885-8.

33. Baron ED, Stern RS, Taylor CR. Correlating skin type and minimum erythema dose. Arch Dermatol 1999;135:1278-9.

34. Lee J, Kim T. Relationship between constitutive skin color and ultraviolet light sensitivity in Koreans. Photodermatol Photo 1999;15:231-5.

35. Leenutaphong V. Relationship between skin color and cutaneous response to ultraviolet radiation in Thai. Photodermatol Photo 1995;11:198-203.

36. González F, Martínez-Escanamé M, Muñoz R, Torres-Álvarez B, Moncada B. Diffuse reflectance spectrophotometry for skin phototype determination. Skin Res Technol 2010;16:397-400.

37. Parra EJ, Kittles RA, Shriver MD. Implications of correlations between skin color and genetic ancestry for biomedical research. Nat Genet 2004;36:S54-60. 